2015

Late Emergence of the First Possession Heuristic: Evidence From a Small-Scale Culture

\author{
lqbal, Prof. Dr. Masud
}

http://hdl.handle.net/10026.1/16597

10.1111/cdev. 12365

Child Development

Wiley

All content in PEARL is protected by copyright law. Author manuscripts are made available in accordance with publisher policies. Please cite only the published version using the details provided on the item record or document. In the absence of an open licence (e.g. Creative Commons), permissions for further reuse of content should be sought from the publisher or author. 
Running head: First possession bias in a small-scale culture

\title{
Late emergence of the first possession heuristic: evidence from a small-scale culture
}

\author{
Patricia Kanngiesser, Federico Rossano, Michael Tomasello \\ Department of Developmental and Comparative Psychology, Max Planck Institute for \\ Evolutionary Anthropology
}

Acknowledgements

We would like to thank Henriette Zeidler and Esther Herrmann for their help and support in Kenya and Nadine Schuhmann for her assistance with data collection in Germany. Finally, we thank the schools and nurseries in Nanyuki and Leipzig, and the children for taking part in our studies. This research was supported by a Marie Curie Intra-European Fellowship to the first author and by the Max Planck Society.

Correspondence concerning this article should be addressed to: Patricia Kanngiesser, Department of Developmental and Comparative Psychology, Max Planck Institute for Evolutionary Anthropology, Deutscher Platz 6, 04103 Leipzig, Germany; Email: kanngiesser@eva.mpg.de

This is a preprint version of the published article: Kanngiesser, P., Rossano, F., Tomasello, M. (2015). Late emergence of the first possession heuristic: Evidence from a small-scale culture.

Child Development, 86(4), 1282-1289. https://doi.org/10.1111/cdev.12365 


\begin{abstract}
Western preschool children often assign ownership based on first possession and some have proposed that this judgment might be an early emerging, innate bias. Five- to nine-year-old children $(n=112)$ from a small-scale group in Kenya (Kikuyu) watched videotaped interactions of two women passing an object. The object's starting position and the women's gestures were varied. Use of the first possession heuristic increased with age and eight- to nine-year-olds performed similarly to German five-year-olds $(n=24)$. Starting position and gestures had no effect. A control study confirmed that five-year-old Kikuyus $(n=20)$ understood the video material. The findings reveal that the first possession heuristic follows different developmental trajectories cross-culturally and stress the role of children's socio-cultural environment.
\end{abstract}

Keywords: first possession, ownership, cross-cultural 


\section{Late emergence of the first possession heuristic: evidence from a small-scale culture}

Property ownership, as opposed to physical possession, is a social institution that regulates access to and use of things. Developmental research in Western urbanized cultures has shown that understanding of ownership emerges at around two to three years of age, when children begin to make inferences about who owns what, independent of physical possession (Blake \& Harris, 2011; Fasig, 2000; Hay, 2006; Tomasello, 1998;), and start to value and defend their property (Gelman, Manczak, \& Noles, 2012; Kanngiesser \& Hood, 2014). Somewhat later, by three to four years of age Western children show an understanding of the social conventions surrounding property (Neary \& Friedman, 2014; Rossano, Rakoczy, \& Tomasello, 2011) and begin to use more sophisticated rules to infer or transfer ownership (Kanngiesser, Gjersoe, \& Hood, 2010; Neary, Friedman, \& Burnstein, 2009).

One of the ownership rules that has received particular attention is the first possession heuristic. Specifically, young Western children will attribute ownership to a person that possessed an object first (Friedman \& Neary, 2008), unless they receive conflicting verbal ownership information (Blake, Ganea, \& Harris, 2012). However, children do not just rely on first possession, but also seem to use it as a cue to reconstruct the historical path of possession (Friedman, van de Vondervoort, Defeyter, \& Neary, 2013; Nancekivell \& Friedman, 2014). The first possession heuristic remains relevant beyond childhood, playing a role in adult ownership attributions (Friedman, 2008; Friedman \& Neary, 2009) and forming the basis of a pivotal legal ruling in North American property law (Pierson v. Post, 1805). In fact, some suggest that respecting first possession may even be an evolved mechanism that humans share with primates and other animals (Brosnan, 2011; Stake, 2004). But the early emergence of the first possession 
heuristic has only been established in industrialized populations that have particular kinds of conventions surrounding private property (Henrich, Heine, \& Norenzayan, 2010).

Compared to the wealth of data from Western populations, cross-cultural data on the development of ownership understanding is still sparse. Furby $(1978,1980)$ found that five- and ten-year-old children from urban North America, Israeli Kibbutzim and urban Israel associated ownership with a sense of control and efficacy. Recently, Zebian and Rochat (2012) showed that three- to five-year-old Palestinian refugee and North American middle class children made similar decisions in land ownership disputes. Finally, both preschoolers from Japan and the UK transferred ownership on the basis of creative labor (i.e., transferred ownership from the owner of the materials to creators who transformed the materials; Kanngiesser, Itakura \& Hood, 2014). The findings to date suggest similarities in ownership understanding across cultures, but little is known about whether these findings will generalize to non-industrialized, small-scale populations where children have very few or no personal possessions. We thus investigated the development of the first possession heuristic in a small-scale African population, the Kikuyu of central Kenya.

The Kikuyu are part of the Bantu people and form the largest ethnic group in Kenya, making up $17 \%$ of the total population (Kenyan National Bureau of Statistics, 2009). Traditionally, the Kikuyu were small-scale farmers and had a well-developed system of land ownership with land being family owned and inherited across generations (Kenyatta, 1965). Even though many Kikuyu today live in urban centers, part of the population still lives in rural areas and subsists on small-scale farming. Kikuyu children in our study were from a rural area, near Mt. Kenya in central Kenya. Most families in the area own plots of land where they grow crops and keep some live-stock. They live in simple, wooden houses with tin roofs and have no 
direct access to electricity. Children rarely have any personal possessions: clothing is shared with siblings and toys - if children possess any at all - are usually self-made such as balls made from rags or cars made from plastic bottles. At three years of age children begin to attend nursery school (though often irregularly) and at approximately six years of age children start with primary school. Lessons are taught in English and teachers talk to children in English, Swahili or Kikuyu.

In our study, we presented five- to nine-year-old Kikuyu children with videos of two young women and an object, varying the start location of the object. Recent findings with Western children have shown that they only use the first possession heuristic if a person possessed an object from the start, but not if a person was simply the first to pick up an object (Friedman et al., 2013). These and other findings have led Nancekivell and Friedman (2014) to conclude that children do no rely on perceptual cues of first possession, but make inferences about the past possession of the object. To test this claim with the Kikuyu children, we used two types of videos: videos where the first possessor entered the scene with the object and videos where she picked up the object from the ground. In addition, transfers of objects often take place in culture-specific ways. For example, in some cultures object transfers are elicited by recipients via requests (so-called "demand sharing cultures"), while in other cultures objects are offered to recipients by sharers (Schegloff, 2007). Since Kikuyu conventions regarding object transfers may differ from Western conventions, we varied whether the first possessor left the object on the ground, offered it to the recipient, or handed it over following a request (Rossano \& Liebal, 2014). Finally, we used video stimuli since Kikuyu children are less familiar with pretend, live stories than Western children and assumed that more naturalistic videos would facilitate their understanding. Moreover, we presented videos without narration to avoid giving any verbal 
ownership cues. We also tested five-year-old German children as a comparison group and to ensure that our video stimuli would elicit comparable responses to the live demonstrations used in previous developmental studies (e.g., Friedman \& Neary, 2008).

\section{Experiment 1}

\section{Method}

\section{Participants}

We tested 112 Kikuyu children aged five to nine (Mean Age $=7$ years, Range $=5-9$ years) from two rural schools near Nanyuki in Laikipia county in central Kenya (see Table 1 for details). One additional six-year-old was excluded because he did not point to the women in the videos. As a comparison group, we also tested 24 German five-year-olds from one urban kindergarten in Leipzig, Germany (see Table 1 for details). German children were mostly from Caucasian, middle-class families.

\section{Procedure}

Instructions. All instructions were translated into Kikuyu (and back-translated by a different native speaker to check for accuracy), recorded by a native speaker and played back from a laptop computer. German and Kikuyu children were tested by German experimenters who used audio-playbacks to instruct children in their respective language. Kikuyu children had experienced play-back instructions from laptops in previous studies and were thus familiar with the general testing set-up.

Pointing warm-up. Children first participated in a warm-up pointing game. This task was introduced to familiarize children with pointing to things on a screen. Children were shown pairs 
of animal pictures (e.g. a lion and an elephant) and asked to point to one of the animals. We showed them four pairs of pictures in total and varied whether the correct picture was displayed on the left (two trials) or the right (two trials).

Main Experiment. Next, children took part in the main experiment, in which they watched videos with short interactions between two young women from the children's respective culture. Children watched two control videos, followed by six test videos. In all videos, the object either started with one of the women (possessor-first) or in the middle between the two women (middle-first; see Figure 1A). The same two women acted in all videos, but differently colored objects were used in each video. Half of the children in each age group watched the possessorfirst videos, and half of the children watched the middle-first videos (between-subjects factor). Moreover, for each object location (possessor-first or middle-first) half of the children watched videos depicting the two women with a ball and half of them watched the videos depicting the women with a necklace (between-subjects factor). We chose a ball and a necklace as they are both objects that Kikuyu children are familiar with.

Each video started with the two women entering the scene from the sides and kneeling/sitting down. In the possessor-first videos, one of the women (first possessor) entered the scene holding the object. In the middle-first videos, the object was shown on the ground and picked up by one of the women (first possessor). In the control videos, the first possessor briefly played with the object and then put it on the ground. Children watched one video with the woman on the right and one video with the woman on the left as first possessor (two videos in total).

In the test videos, the first possessor briefly played with the object, passed it to the second woman, who also briefly played with the object and then put it on the ground between the two women. We varied the gesture with which the first woman passed the object to the second 
woman: she either put the object on the ground for the second woman to pick up (ground), she gave the object to the second woman (give), or she handed over the object following a request (an outstretched hand) by the second possessor (request; see Figure 1B). All videos were presented without sound and narration to avoid providing any verbal ownership cues. Children watched two videos for each of the three gestures - one video with the person on the left as first possessor and one trial with the person on the right as first possessor. Children thus watched six test videos in total, in one of six different video orders (We randomly generated six orders out of 720 possible ones, the only constraint being that each video was presented at the start once).

At the start of the main experiment, children were instructed that they would watch videos on the computer and that the videos would show two people and a ball/necklace. They were then told that they would be asked to point to the owner of the object at the end of each video. After each video, children were shown a still image of the two people with the object between them. Kikuyu children were then asked "Nu mwene mubira/mugathi? Ndakuhoya orota mundu uria mwene mubira/mugathi!" (Engl.: "Who is the owner of the ball/necklace? Please point to the owner of the ball/necklace."), while German children were asked "Wem gehört der Ball/die Kette? Bitte zeige auf den Besitzer des Balls/der Kette! (engl.: "Who owns the ball/necklace? Please point to the owner of the ball/necklace."). If children did not select one of the women, the instructions were repeated up to two times and children were encouraged to point to the women on the screen. Kikuyu children never gave verbal responses and German children rarely did, in which case they were encouraged by the experimenter to point to one of the women. Kikuyu children received cookies and German children received stickers as a thank you for participating. 


\section{Data coding and analyses}

All sessions were videotaped. We used live coding and coding from video tapes and coded whether children pointed to the first possessor (first possessor $=1$, other response $=0$ ). If pointing was ambiguous (e.g. the child rapidly pointed to both women), pointing was scored as "unclear" and coded as 0 . In total, 6 trials out of $1088(0.6 \%)$ were scored as unclear. $25 \%$ of the videos were coded by a second observer for reliability purposes $(\kappa=.99)$.

We first analyzed the data using Generalized Linear Mixed Models (GLMM), using the lme4 package (Bates, Maechler, Bolker, \& Walker, 2013) in R (version 3.0.2, R Development Core Team, 2013). We used a binomial error structure and the logit link function. We included variables of interest such as start position (possessor-first, middle-first), gesture (ground, give, request), population (Kikuyu, German), and age (in years) as fixed effects and participant ID as a random effect. In addition, we included gender, object (ball, necklace) and trial number as control variables. We compared full and null models (i.e., models that only included the control variables gender, object and trial number) with likelihood ratio tests using the ANOVA procedure in $\mathrm{R}$.

\section{Results and Discussion}

\section{Warm-up and control videos}

In the warm up pointing game, Kikuyu and German children pointed to the correct pictures significantly more often than expected by chance (Kik 5: 77\%, Kik 6: 83\%, Kik 7: 88\%, Kik 8: 91\%, Kik 9: 95\%, Ger 5:100\%), ps $<.001$. Kikuyu children mainly made errors regarding the last two animal pictures (giraffe: $51 \%$ of errors, zebra: $36 \%$ of errors), but were able to understand the playback instructions and respond by pointing to the correct objects on a 
computer screen. After having watched the control videos in which only one woman possessed the object (two videos in total), children pointed to the first possessor significantly more often than expected by chance (Kik 5: 91\%, Kik 6: 71\%, Kik 7: 70\%, Kik 8: 83\%, Kik 9: 90\%, Ger $5: 73 \%)$, ps $<.019$. This suggests that Kikuyu were able to appropriately respond to the ownership question when possession of the object was unambiguous.

\section{Main Results}

We first investigated whether Kikuyu children's ownership attributions were affected by the object's start location, the transfer gesture, and by children's age (full model vs. null model comparison: $\left.\chi^{2}(4)=9.45, p=.051\right)$. Older Kikuyu children were significantly more likely to assign ownership to the first possessor than younger children, $Z=2.93, p=.003$. Overall, children were significantly more likely to assign ownership to first possessors for balls than for necklaces, $Z=2.66, p=.008$; and girls were significantly more likely to attribute ownership to first possessors than boys, $Z=2.64, p=.008$. However, the object's start location did not have a significant effect, $Z=0.51, p=.607$, nor did gestures (give $v$ s. ground: $Z=0.93, p=.355$; request $v s$. ground: $Z=0.08, p=.933$; give $v s$. request: $Z=0.84, p=.399$ ), or trial number, $Z=$ $0.19, p=.853$.

Next, we investigated effects of culture by combining the data from five-year-old Kikuyu and five-year-old German children in a model (null vs. full model comparison: $\chi^{2}(4)=4.30, p=$ .367). We found that German children were significantly more likely to attribute ownership to first possessors than Kikuyu children $(Z=2.00, p=.046)$. Five-year-olds from both populations were more likely to apply the first possession rule to balls than to necklaces, $Z=1.65, p=.098$. The remaining factors in the model had no significant effects $(Z s<1.38, p>.169)$. 
Since gesture or starting position had no significant effect on children's responses, we combined their responses to the six videos (range $=0-6$ ) and compared scores in each age group to chance (see Figure 2). Five- to seven-year-old Kikuyu children assigned ownership to first possessors at chance levels, $t_{K i k 5}(21)=0.56, p=.584, t_{K i k 6}(20)=0, p>.999, t_{K i k}(24)=0.56, p=$ .584 . By eight and nine years of age, Kikuyu children showed a trend for assigning ownership to the first possessor above chance, $t_{K i k 8}(23)=1.71, p=.101, t_{K i k g}(19)=1.76, p=.095$, as did German children, $t_{\text {Ger } 5}(23)=1.87, p=.074$. Since our analyses revealed a significant effect of object, we conducted separate analyses for ball and necklace videos, respectively. Kikuyu eightand nine-year-olds assigned ownership to first possessors significantly (or marginally significantly) above chance levels for ball videos, $t_{\text {Kik__Ball }}(11)=2.11, p=.058, t_{\text {Kikg_Ball }}(9)=$ $2.69, p=.025$ (younger Kikuyu children: $p s_{-}$Ball $>.304$; German children: $t_{\text {Ger5_Ball }}(11)=1.76, p$ $=.105$ ). Responses to necklace videos did not differ significantly from chance (irrespective of age group and culture), $p s_{-}$Necklace $>.190$.

Finally, we investigated individual strategies; that is, we classified children who assigned ownership to the first possessor on five or more trials (out of six) as using a first possession strategy, children who assigned ownership to the last possessor on five or more trials as using a last possession strategy, and all remaining children as using a random strategy (see Figure 3). Kikuyu children's use of the first possession strategy increased from $14 \%$ at age five to $50 \%$ at age nine, while random responses decreased from $60 \%$ to $30 \%$ (use of the last possession strategy was on average 20\% across all ages). In comparison, $54 \%$ of German five-year-olds used a first possession strategy, 25\% responded randomly and $21 \%$ used a last possession strategy. 
Taken together, our findings show that ownership attributions based on first possession increased with age in a traditional, non-Western population. Five-year-old Kikuyu children used first possession strategy less often than German children of the same age and did not reach comparable rates until eight to nine years of age. These findings indicate a stark contrast to Western children who already apply the first possession heuristic between two to three years of age (Friedman \& Neary, 2008). However, it is possible that young Kikuyu children did not use the first possession heuristic because they failed to understand the videos. We thus repeated the experiment with a simple memory question (i.e. who had possessed the object first).

\section{Experiment 2}

\section{Methods}

\section{Participants}

Twenty Kikuyu children took part in the experiment (Age $=5$ years; see Table 1 for details). All children had participated in Experiment 1 five months earlier.

\section{Procedure}

The procedure in Experiment 2 was identical to Experiment 1 with the exception that in the main task, children were asked to point to the person who had the ball first. We also used new animal pictures in the pointing warm up.

\section{Data Coding}

We coded whether children pointed to the person who had the object first (inter-rater agreement: $\kappa=.93)$. 
Results and Discussion

\section{Warm-up and control videos}

In the warm up pointing game, children pointed to the correct picture $100 \%$ of time. For the two control videos, children pointed to the first possessor significantly more often than expected by chance $\left(\mathrm{Kik}_{\mathrm{Control}} 5: 90 \%\right), t(19)=8.72, p<.001$.

\section{Main Results}

When asked to point to the person who had the object first, five-year-old Kikuyu children pointed to the first possessor on average $81 \%$ of the time across the six test videos (Mean Score $=4.85, S D=1.36$ ). Children chose the first possessor significantly more often than expected by chance, $t(19)=5.97, p<.001$. They also chose the first possessor significantly more often than in Experiment 1, $t(19)=5.90, p<.001$. By five years of age, Kikuyu children correctly remembered the first possessor, indicating that they were able to understand the videos.

\section{General Discussion}

The first possession heuristic has been widely discussed as an early emerging ownership bias that may be innate and possibly shared with other animal species (Blumenthal, 2010; Brosnan, 2011; Friedman, 2008; Friedman \& Neary, 2008; Stake, 2004). To date, developmental evidence supporting this claim has been derived primarily from children in Western industrialized populations. We found that young Kikuyu children from a traditional, small-scale population in Kenya showed an age-dependent increase in using the first possession heuristic: young Kikuyu children used the first possession heuristic less often than their German peers and did not use it 
consistently until eight to nine years of age. In comparison, Western children have previously been found to use this heuristic as early as two years of age (Friedman \& Neary, 2008). Our findings challenge notions of the first possession heuristic as an early emerging innate bias. Rather our findings stress the role of children's socio-cultural environment in shaping the emergence and the development of the first possession heuristic.

To date, cross-cultural studies on the development of ownership understanding have found similarities in children's conception of the meaning of ownership (Furby, 1978; 1980), ownership transfers on the basis of creative labor (Kanngiesser et al., 2014), and their decisions in land ownership disputes (Zebian \& Rochat, 2012). At this point we can only speculate why the first possession heuristic emerges late in Kikuyu children. Even though the Kikuyu have a wellestablished system of family land-ownership, Kikuyu children have very few - if any - personal possessions. Kikuyu children are thus less likely to experience control over the use of and access to objects than children with more abundant personal possessions. In fact, control of possessions has previously been found to be one of the main characteristics that children from different populations associate with ownership of objects (Israeli kibbutzim, Israeli non-kibbutzim, urban US; Furby, 1978). It is thus possible that children growing up in environments that provide many opportunities from early on to experience control of possessions develop a precocious understanding of ownership compared to children growing up in environments that provide less opportunities to do so.

Note, however, that our data only suggest that young Kikuyu children fail to apply the first possession rule to third party scenarios (Friedman \& Neary, 2008). They may, however, possess a more implicit understanding of first possession and may respect and enforce it in their daily social interactions with their siblings and peers. Moreover, young Kikuyu children 
probably share with other children a propensity for wanting to possess and control things (Rochat, 2011) and may value their own possessions more than other's possessions (Gelman, et al., 2012).

In contrast to other studies on first possession we found that the object's start location did not have an effect on children's ownership responses (Friedman et al., 2013). Kikuyu and German children in our study used the first possession heuristic irrespective of whether the first possessor entered with the object or whether she picked it up from the middle. This finding questions claims that children do not just rely on perceptual cues (i.e. who is first seen with an object) but rather make inferences about prior possession (Friedman et al., 2013; Nancekivell \& Friedman, 2014). One possibility for the divergent results is that previous studies used narratives in addition to visual stimuli, which may have provided subtle (non-perceptual) cues to ownership. Recent findings that four-year-olds readily override physical cues when ownership is explicitly stated (Blake et al., 2012) offer tentative support for this suggestion.

Apart from effects of age and culture, we found that children applied the first possession heuristic more often to balls than to necklaces and that girls used it more often than boys. Balls and necklaces were specifically chosen because they are familiar to Kikuyu children. However, we could not rule out the possibility that subtle differences in the conventions surrounding these two objects exist, which may have impacted ownership decisions. Previous studies have found that children's decisions about whether an object is owned differ for natural kinds and artefacts, but further differences within object categories have not been documented to date (Neary, van Vondervoort, \& Friedman, 2012). While we used different objects, gestures and start locations in our videos, we did not vary the gender of the actors. All of our videos showed interactions between two women, and it is possible that this triggered different gender stereotypes in boys 
and girls. Western children have been found to use gender stereotypes to guide their ownership inferences (e.g. a boy is more likely to own a truck than a girl; Malcolm, Defeyter, \& Friedman, 2014), but to our knowledge systematic differences in boys' and girls' ownership decisions have not been found and may need further exploration.

Most evidence on the development of children's ownership concepts is based on studies with Western children. Numerous studies have shown that from two years of age first possession plays an important role in Western children's ownership conflicts and defensive behavior (Eisenberg-Berg, Haake, \& Bartlett, 1981; Ramsey, 1987; Ross, 1996, 2013) and in their inferences in third party ownership scenarios (Friedman \& Neary, 2008). However, our evidence suggests that this developmental pattern may not be shared universally and may follow different trajectories depending on the socio-cultural environment children grow up in - at least with regards to third party ownership inferences. It is unclear to date whether other aspects of ownership such as recognizing and learning ownership relationship (Blake \& Harris, 2011; Fasig, 2000) or understanding different ownership rights (Kanngiesser \& Hood, 2014; Neary \& Friedman, 2014; Rossano et al., 2011) develop in a similar manner cross-culturally. Future studies could particularly focus on comparing the development of ownership concepts in smallscale groups with very distinct property regimes (e.g. by comparing hunter-gatherer groups with sedentary, agricultural groups). 


\section{References}

Bates, D., Maechler, M., Bolker, B., \& Walker, S. (2013). Linear mixed-effects models using Eigen and S4. R package version version 1.0-5. Retrieved from http://CRAN.R-

project.org/package $=\operatorname{lme} 4$

Blake, P., \& Harris, P. (2011). Early representations of ownership. New Directions for Child and Adolescent Development, 2011, 39-51. doi:10.1002/cd.295

Blake, P. R., Ganea, P. A., \& Harris, P. L. (2012). Possession is not always the law: With age, preschoolers increasingly use verbal information to identify who owns what. Journal of Experimental Child Psychology, 113, 259-272. doi:10.1016/j.jecp.2012.06.008

Blumenthal, J. A. (2010). Property law: A cognitive turn. Psychonomic Bulletin \& Review, 17(2), 186-191. doi: 10.3758/PBR.17.2.186

Brosnan, S. (2011). Property in nonhuman primates. New Directions for Child and Adolescent Development, 2011, 9-22. doi: 10.1002/cd.293

Eisenberg-Berg, N., Haake, R., \& Bartlett, K. (1981). The effects of possession and ownership on the sharing and proprietary behaviors of preschool children. Merrill-Palmer Quarterly: Journal of Developmental Psychology, 27, 61-68. doi: 10.2307/23084509

Fasig, L. G. (2000). Toddlers' understanding of ownership: Implications for self-concept development. Social Development, 9, 370-382. doi: 10.1111/1467-9507.00131

Friedman, O. (2008). First possession: An assumption guiding inferences about who owns what. Psychonomic Bulletin \& Review, 15, 290-295. doi: 10.3758/PBR.15.2.290

Friedman, O., \& Neary, K. R. (2008). Determining who owns what: Do children infer ownership from first possession? Cognition, 107, 829-849. doi:10.1016/j.cognition.2007.12.002 
Friedman, O., \& Neary, K. R. (2009). First possession beyond the law: Adults' and young children's intuitions about ownership. Tulane Law Review, 83, 679-690.

Friedman, O., van de Vondervoort, J. W., Defeyter, M., \& Neary, K. R. (2013). First Possession, History, and Young Children's Ownership Judgments. Child Development, 84, 1519-1525. doi: $10.1111 /$ cdev.12080

Furby, L. (1978). Possession in humans: An exploratory study of its meaning and motivation. Social Behavior and Personality: An International Journal, 6, 49-65. http://dx.doi.org/10.2224/sbp.1978.6.1.49

Furby, L. (1980). The Origins and Early Development of Possessive Behavior. Political Psychology, 2, 30-42. http://dx.doi.org/10.2307/3790969

Gelman, S. A., Manczak, E. M., \& Noles, N. S. (2012). The Nonobvious Basis of Ownership: Preschool Children Trace the History and Value of Owned Objects. Child Development, 83, 1732-1747. doi: 10.1111/j.1467-8624.2012.01806.x

Hay, D. F. (2006). Yours and mine: Toddlers' talk about possessions with familiar peers. British Journal of Developmental Psychology, 24, 39-52. doi: 10.1348/026151005X68880

Hay, D. F., Nash, A., \& Pedersen, J. (1983). Interactions between Six-Month-Old Peers. Child Development, 54, 557-562. http://dx.doi.org/10.2307/1130042

Henrich, J., Heine, S., \& Norenzayan, A. (2010). The weirdest people in the world. Behavioral and Brain Sciences, 33, 61-83. http://dx.doi.org/10.1017/S0140525X0999152X

Kanngiesser, P., Gjersoe, N., \& Hood, B. M. (2010). The Effect of Creative Labor on PropertyOwnership Transfer by Preschool Children and Adults. Psychological Science, 21, 12361241. doi: $10.1177 / 0956797610380701$ 
Kanngiesser, P., \& Hood, B. M. (2014). Young children's understanding of ownership rights for newly made objects. Cognitive Development, 29, 30-40. doi:10.1016/j.cogdev.2013.09.003

Kanngiesser, P., Itakura, S., \& Hood, B.M. (2014). The effect of labour on ownership decisions in two cultures: Developmental evidence from Japan and the United Kingdom. British Journal of Developmental Psychology, 32, 320-329. doi:10.1111/bjdp.12043

Kenyatta, J. (1965). Facing Mt. Kenya: The tribal life of the Gikuyu. New York, NY: Random House.

Kim, S., \& Kalish, C. W. (2009). Children's ascription of property rights with changes of ownership. Cognitive Development, 24, 322-336. doi:10.1016/j.cogdev.2009.03.004

Malcolm, S.L., Defeyter, M.A., \& Friedman, O. (2014). Children and adults use gender- and age-stereotypes in ownership judgments. Journal of Cognition and Development, 15, 123135. doi:10.1080/15248372.2012.728545

Nancekivell, S. E., \& Friedman, O. (2014). Preschoolers Selectively Infer History When Explaining Outcomes: Evidence From Explanations of Ownership, Liking, and Use. Child Development. 85, 1236-1247. doi:10.1111/cdev.12170

Neary, K. R., van de Vondervoort, J., \& Friedman, O. (2012). Artifacts and natural kinds: Children's judgments about whether objects are owned. Developmental Psychology, 48, 149158. http://dx.doi.org/10.1037/a0025661

Neary, K. R., \& Friedman, O. (2014). Young Children Give Priority to Ownership When Judging Who Should Use an Object. Child Development, 85, 326-337. doi:10.1111/cdev.12120 
Neary, K. R., Friedman, O., \& Burnstein, C. L. (2009). Preschoolers Infer Ownership From Control of Permission. Developmental Psychology, 45, 873-876.

http://dx.doi.org/10.1037/a0014088

Pierson v. Post, 3 Cai. R. 175, (N.Y. 1805)

R Development Core Team. (2013). R: A language and environment for statistical computing. Vienna, Austria. Retrieved from http://www.R-project.org

Ramsey, P. G. (1987). Possession Episodes in Young Children's Social Interactions. Journal of Genetic Psychology, 148, 315-325. doi:10.1080/00221325.1987.9914561

Rochat, P. (2011). Possession and morality in early development. New Directions for Child and Adolescent Development, 2011, 23-38. doi:10.1002/cd.294

Ross, H. (1996). Negotiating principles of entitlement in sibling property disputes. Developmental Psychology, 32(1), 90-101. http://dx.doi.org/10.1037/0012-1649.32.1.90

Ross, H. (2013). Effects of Ownership Rights on Conflicts Between Toddler Peers. Infancy, 18, 256-275. doi:10.1111/j.1532-7078.2012.00121.x

Rossano, F., Rakoczy, H., \& Tomasello, M. (2011). Young children's understanding of violations of property rights. Cognition, 121, 219-227. doi:10.1016/j.cognition.2011.06.007

Rossano, F. \& Liebal, K. (2014). "Requests" and "offers" in orangutans and human infants. In P. Drew \& E. Couper-Kuhlen (Eds.) Requesting in Social Interaction (pp. 333 - 362).

Schegloff, E. A. (2007). Sequence organization in interaction: Volume 1: A primer in conversation analysis. New York: Cambridge University Press.

Stake, J. E. (2004). The property 'instinct'. Philosophical Transactions of the Royal Society B: Biological Sciences, 359, 1763-1774. doi:10.1098/rstb.2004.1551 
Tomasello, M. (1998). One child's early talk about possession. Typological Studies in Language, $36,349-373$.

Zebian, S., \& Rochat, P. (2012). Judgment of land ownership by young refugee Palestinian and U.S. children. International Journal of Behavioral Development, 36, 449-456.

doi:10.1177/0165025412450526 


\section{Tables and Figures}

Table 1 Overview Children

\begin{tabular}{lrrrr}
\hline Population & Age & Female & Male & Total \\
\hline \multicolumn{5}{c}{ Experiment 1} \\
Kikuyu & 5 & 12 & 10 & 22 \\
Kikuyu & 6 & 7 & 14 & 21 \\
Kikuyu & 7 & 17 & 8 & 25 \\
Kikuyu & 8 & 10 & 14 & 24 \\
Kikuyu & 9 & 3 & 17 & 20 \\
German & 5 & 12 & 12 & 24 \\
Kikuyu & Experiment 2 & & \\
& 5 & 11 & 9 & 20
\end{tabular}




\section{Figure Captions}

Figure 1 Example of screen shots showing (A) the first possession and middle first condition, and (B) the three different gestures (ground, give, request) used in the videos.

Figure 2 Average sum scores (+ SEM) of ownership attribution to the first possessor for children who watched ball (black bars) and necklace videos (grey bars). The dotted line represents chance (i.e. a score of 3).

Figure 3 Ownership strategies used by children: first possession strategy (sum score of 5 or more), last possession strategy (sum score of 1 or less) or random strategy (sum scores between 2 and 4). 
Figure 1
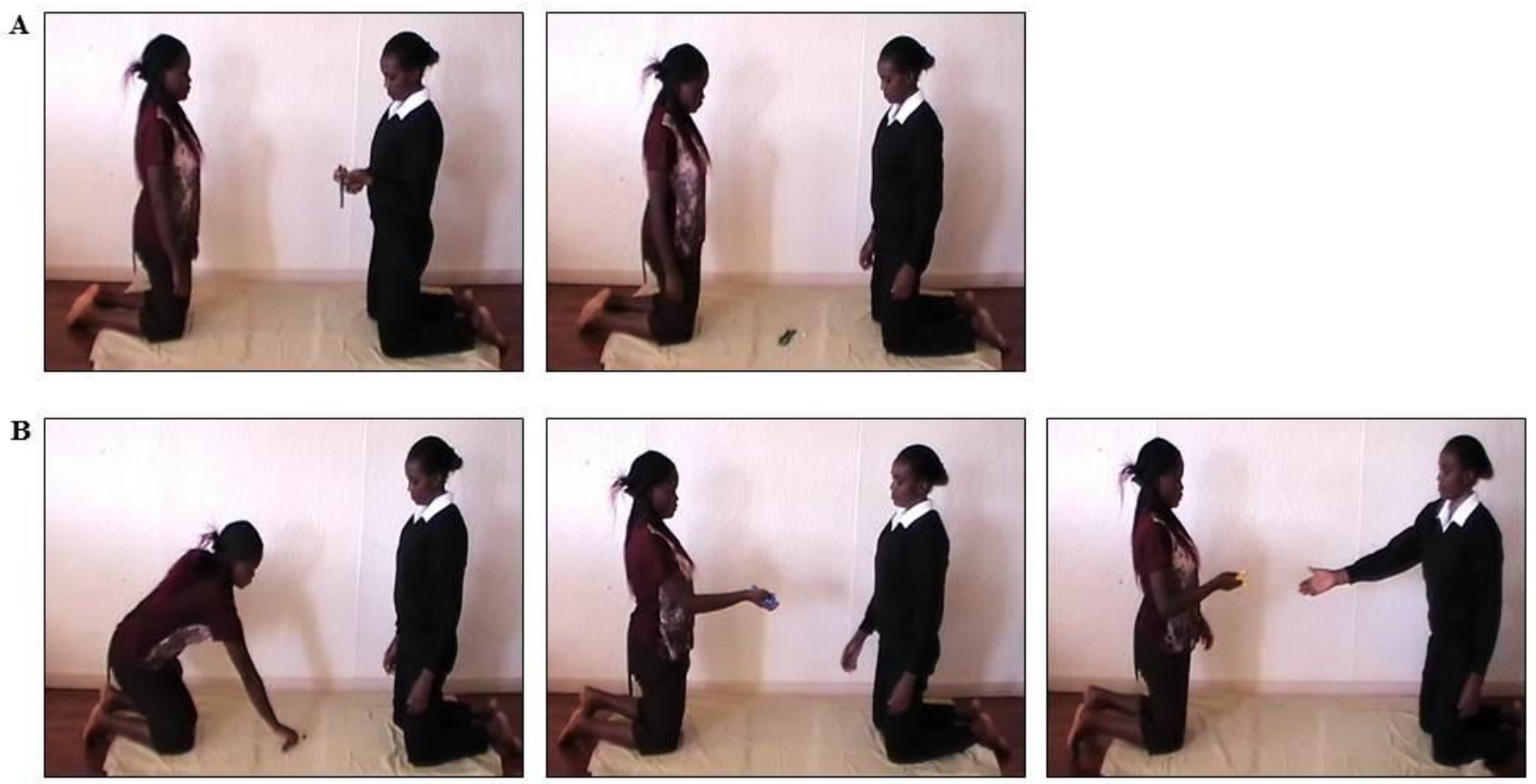

Figure 2

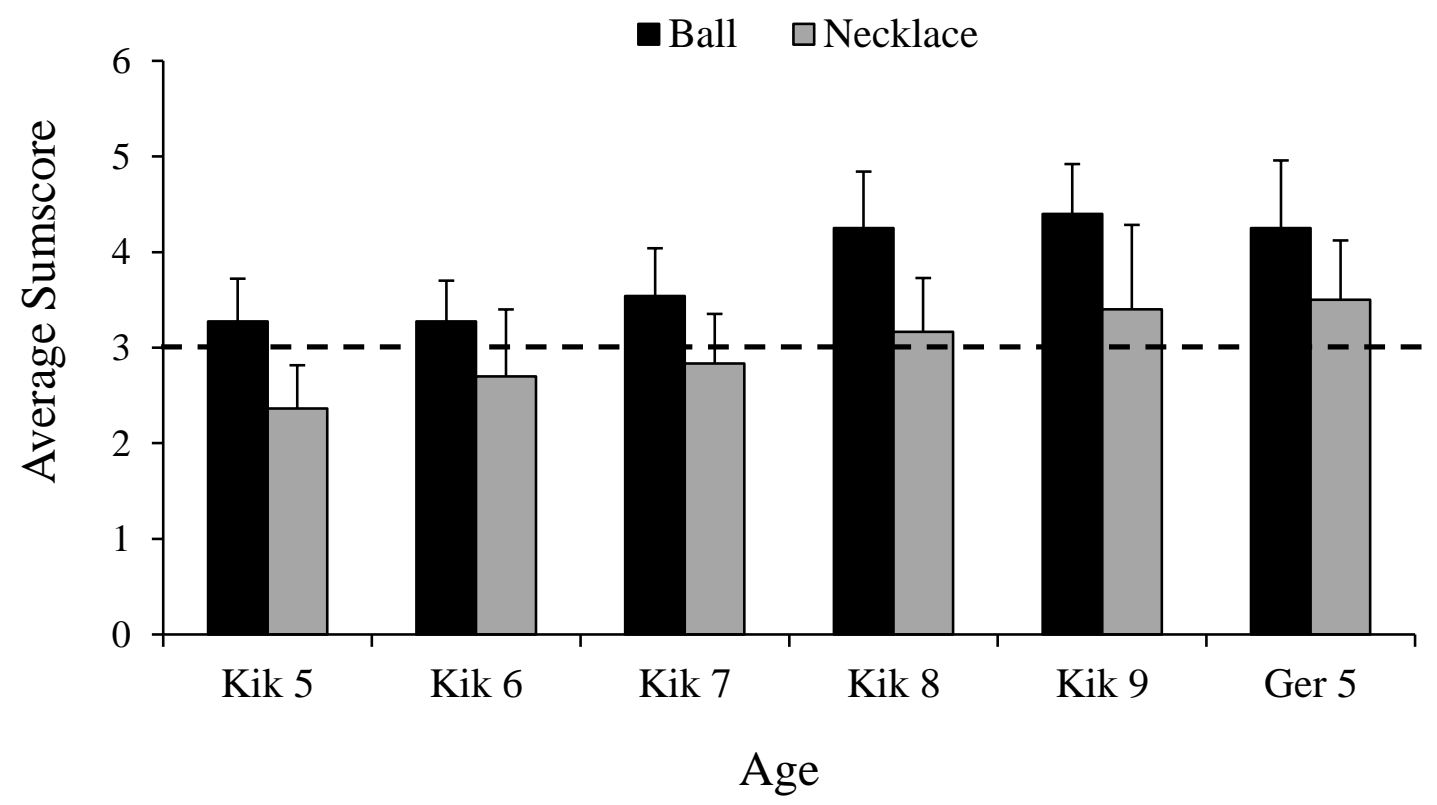


Figure 3

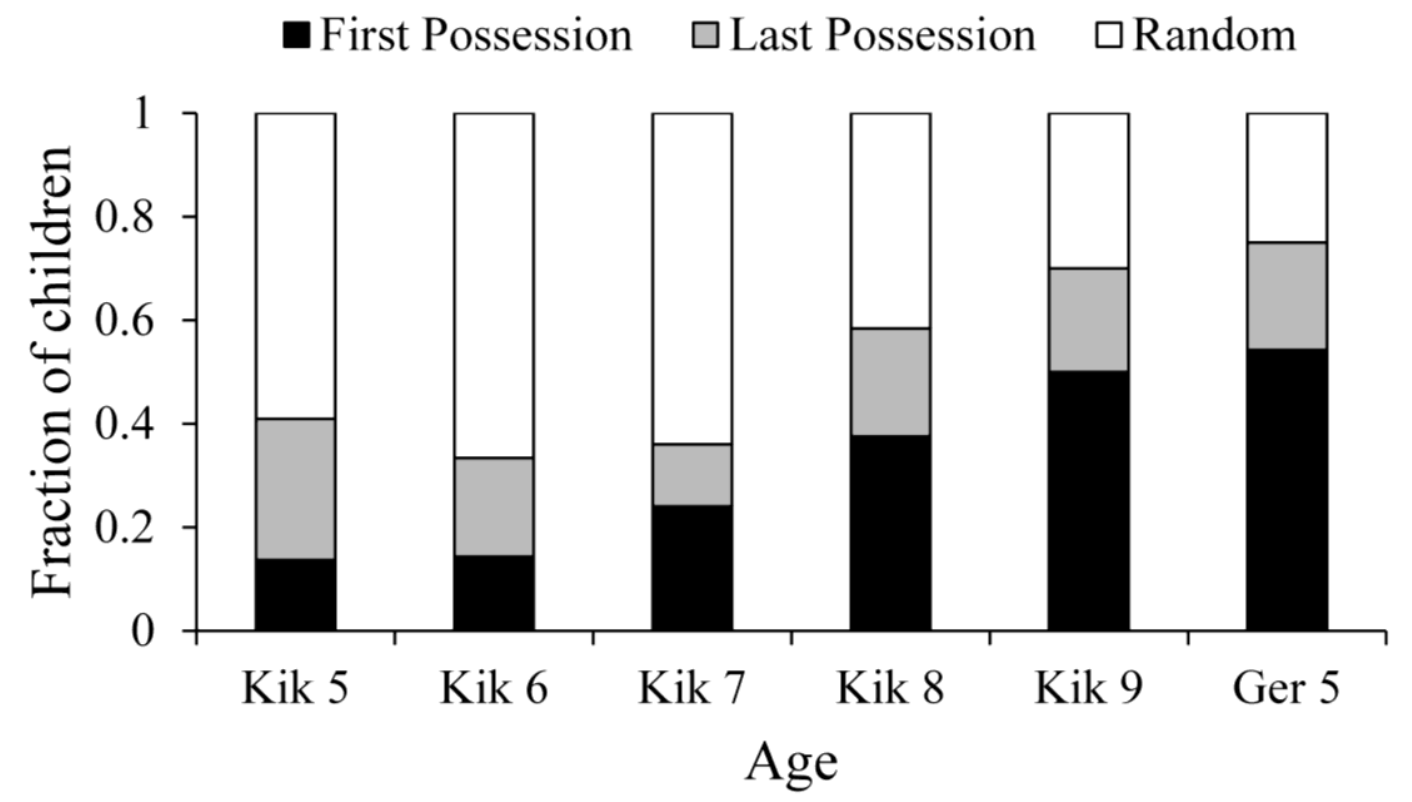

